\title{
A construção do conceito de criminoso na sociedade capitalista: um debate para o Serviço Social
}

\author{
Arnaldo Xavier \\ Universidade Federal de Santa Catarina (UFSC)
}

\begin{abstract}
A construção do conceito de criminoso na sociedade capitalista: um debate para o Serviço Social Resumo: A violência, de alguma forma, sempre esteve presente na história da humanidade, assumindo características diferentes nos diversos contextos sociais e econômicos. Ela é o foco do assunto discutido neste artigo ${ }^{1}$, sobretudo, em sua vertente urbana na sociedade capitalista contemporânea. Analisa-se, com base na história do direito penal, a centralidade que o conceito de criminoso alcançou no decorrer da história da sociedade moderna. A partir dos dados observados, busca-se refletir sobre a irrupção da violência individual em detrimento das demais formas de violência, presentes na ordem societária capitalista. Examina-se, no segmento, como os processos de criminalização e de controle social, empregados pelo aparato estatal elegem um inimigo comum a ser combatido: o delinqüente. Com o aporte teórico da criminologia crítica, discutem-se as contribuições que essas idéias trazem para o Serviço Social e como o assistente social pode apropriar-se delas em seu processo de formação e exercício profissional.
\end{abstract}

Palavras-chave: criminologia crítica, criminalização, Serviço Social, violência.

The Construction of the Concept of the Criminal in Capitalist Society: a Debate for Social Work

Abstract: Violence, in some form, has always been present in human history, assuming different characteristics in different social and economic contexts. It is the focus of the subject discussed in this article ${ }^{1}$, above all in contemporary urban capitalist society. Based on a history of criminal law, this paper analyzes the central place of the concept of the criminal during the history of modern society. Based on the observed data the article reflects on the eruption of individual violence in detriment to other forms of violence present in the capitalist social order. It examines how the processes of criminalization and social control employed by the state apparatus elect a common enemy to be combated: the delinquent. Supported by critical criminology theory, it discusses the contributions of these ideas to Social Work and how social workers can use them in their education and professional activity.

Key words: critical criminology, criminalization, Social Work, violence. 
A lei penal não é igual para todos, o status de criminoso aplica-se de modo desigual aos sujeitos, independentemente do dano social de suas ações e da gravidade das infrações à lei penal realizada por eles. Alessandro Baratta

\section{Introdução}

Pensar as questões da violência é, muitas vezes, relacioná-las com o crime, o criminoso e a sensação de insegurança. Comumente desse debate, excluem-se as demais relações que promovem ou contribuem para as expressões da violência, sejam elas de classe, sociais, econômicas ou históricas. A discussão apresentada objetiva pensar em como o Serviço Social se insere nesse debate, uma vez que seu profissional é circunstancialmente, chamado a intervir em espaços mediados por situações de violência, e sob quais aspectos ocorre essa interação. Propõe-se uma reflexão sobre a construção do conceito de criminoso a partir da análise dos paradigmas modernos do direito penal e sobre como esse aporte teórico pode oxigenar a questão sobre o que é, ou não é, considerado violência em nossa sociedade.

O Serviço Social surge como profissão na primeira metade do século 20, com a primeira turma de assistentes sociais formada em 1938 (CARVALHO; IAMAMOTO, 2004). Nasceu aliado à estrutura da Igreja Católica e no seio da classe burguesa, chegou ao fim do século 20 - após um longo período de lutas, processos de reconceituação, construções históricosociais - como uma profissão laica, objetivando, por meio da intervenção profissional, contribuir para transformar a realidade social. Deveras, tal objetivo se mostra complexo e desafiador, e não foi diferente ao longo de toda a história da profissão. Entende-se que, nesse sentido, o Serviço Social é chamado a mediar o que aparentemente é 'imediável', ou seja, a atuar nas contradições da sociedade capitalista, nas quais ele mesmo está situado, a fim de minimizar seus reflexos na vida material dos sujeitos que demandam sua ação profissional. E não apenas isso, mas promover esses sujeitos e, em conseqüência, a própria sociedade, com meios de construir uma outra realidade, pautada em relações de eqüidade e justiça. $\mathrm{O}$ assistente social se configura, afirma Iamamoto (2005), como um profissional especializado, um trabalhador que vende sua força de trabalho para entidades que dela demandam.

O processo de formação do assistente social apresenta-se como um locus privilegiado, onde o estudante apropria-se de aportes teórico-metodológico, ético-político e técnico-operativo que o habilitarão a intervir na realidade social.

Parafraseando Iamamoto (2005, p. 168), pode-se dizer que o que move essas reflexões aqui postas é a preocupação de
[...] construir, no âmbito do Serviço Social, uma proposta de formação profissional conciliada com os novos tempos, radicalmente comprometida com os valores democráticos e com a prática de construção de uma nova cidadania na vida social, isto é, de um novo ordenamento das relações sociais.

Diante de uma realidade desafiadora, a discussão sobre a violência se faz pertinente, sendo relevante, antes, situar tal conceito no bojo da sociedade capitalista. Para isso, analisaremos a construção do conceito de criminoso e a sua importância para o debate da violência.

\section{O criminoso: do paradigma etiológico à crimi- nologia crítica}

De acordo com a construção histórica do direito penal, a figura do criminoso personifica-se na figura do homem delinqüente da Escola Positiva no século 19, onde se destacam as idéias de Lombroso (2001), Ferri (1931) e Garofalo (1983). Esta corrente de pensamento trazia para o centro do debate a figura do criminoso, deixando a problemática da criminalidade em segundo plano, invertendo a análise realizada, até então, pela Escola Clássica, que não individualizava as causas do crime. Na análise do delito pela Escola Clássica, o crime "[...] surgia da livre vontade do indivíduo, não de causas patológicas e, por isso, do ponto de vista da liberdade e da responsabilidade moral pelas próprias ações, o delinqüente não era diferente, [...] do indivíduo normal"' (BARATTA, 2002, p. 31). O que justificava essa inversão, segundo Ferri (1931), era o delinqüente revelar uma personalidade perigosa, fazendo necessário o uso de uma defesa social apropriada, com uma dupla função: proteger a sociedade do mal produzido por ele e coibir novos delitos latentes.

A criminologia lombrosiana buscava, entre outras coisas, " [...] estabelecer uma divisão entre o 'bom' e o 'mau' cidadão, numa concepção patológica sobre a criminalidade, que visava justificar a pena como meio de defesa social e com fins socialmente úteis" (PAULA, 2007, p. 23). Sob essa concepção, o criminoso passa a ser

[...] um homem causalmente determinado e, como tal erigido no principal objeto criminológico. Estabelece-se dessa forma uma linha divisória entre o mundo da criminalidade - composto por uma minoria de sujeitos potencialmente perigosos e anormais - e o mundo da normalidade - representada pela 'maioria' na sociedade (ANDRADE, 1997, p. 67 , grifo da autora).

Para essa escola criminológica, o criminoso possui em si sinais natos que o definem como tal. Em síntese, 
esse paradigma criminológico opera com a visão maniqueísta do bem e do mal na sociedade e com o consenso de que não há problemas no Direito Penal, antes, nos indivíduos que o violam (ANDRADE, 2003).

Ao longo do século 20, sobretudo a partir dos anos 1960, tem-se a desconstrução desse paradigma etiológico com a introdução das teorias do labelling approach ${ }^{2}$. O paradigma positivo (etiológico) já vinha sofrendo uma revisão desde o início daquele século pela criminologia norte americana com influências da sociologia cultural e de correntes de origem fenomenológicas, bem como por reflexões históricas e sociológicas sobre o fenômeno criminal (ANDRADE, 2003).

Como tese central modelada pelo interacionismo simbólico e o construtivismo social, o labelling approach afirma que

[...] o desvio - e a criminalidade - não é uma qualidade intrínseca da conduta ou uma entidade ontológica pré-constituída à reação (ou controle) social, mas uma qualidade (etiqueta) atribuída a determinados sujeitos através de complexos processos de interação social; isto é, de processos formais e informais de definição e seleção (ANDRADE, 1997, p. 205).

A criminalidade apresenta-se como um status dado a alguns sujeitos, é parte de um processo duplo que, inicialmente, define de forma legal o que é crime, atribuindo a algumas condutas o caráter criminal. Posteriormente, seleciona estes sujeitos conferindo-lhes uma etiqueta que os estigmatiza como criminosos, entre os muitos com as condutas criminalizáveis (ANDRADE, 2003). Uma conduta não é criminal em si mesma e, muito menos, seu autor um criminoso nato. A atribuição do caráter criminal a uma conduta e o posterior rótulo de criminoso ao seu autor dependerá de certos processos sociais de definição e de seleção.

O processo de etiquetamento e rotulação é percebido, segundo Becker (1971 apud VELHO, 1974, p. 24), como uma construção social na medida em que

\footnotetext{
[...] os grupos sociais criam o desvio ao estabelecer as regras cuja infração constitui desvio e ao aplicálas a pessoas em particular, marcando-as como outsiders (estranhos). Sob tal ponto de vista, o desvio não é uma qualidade do ato que a pessoa faz, mas sim a conseqüência da aplicação por outrem de regras e sanções ao transgressor. O desviante é aquele a quem tal marca foi aplicada com sucesso, o comportamento assim definido por pessoas concretas.
}

Pode-se deduzir então, que o crime é produto da reação social e a criminalidade uma construção seletiva e desigual, nesse aspecto, aborda-se o processo de criminalização e o criminalizado, ao invés de centrar-se a discussão na criminalidade e no criminoso (ANDRADE, 2003). Porém, para entendermos os processos de criminalização, não basta apenas entender o crime e o comportamento desviante como produto da reação social, é fundamental pensá-lo conectado com toda realidade estrutural-social, política e econômica. Pois, se afirmarmos que o delinqüente se faz apenas pelo processo de criminalização, estaremos negligenciando o fato de a ação desviante ser primeiramente expressão de um conflito social. Desta forma, o reconhecimento dos limites postos pelas teorias do labelling nas análises macrossociológicas abriu caminhos para o surgimento da criminologia crítica que, como informa Andrade (1997, p. 217), recupera "a análise das condições objetivas, estruturais e funcionais que originam, na sociedade capitalista, os fenômenos de desvio, interpretando-os separadamente, conforme se tratem de condutas das classes subalternas ou conduta das classes dominantes". Em suma, a criminalidade - segundo a visão da criminologia crítica - revela-se

[...] como um status atribuído a determinados indivíduos, mediante uma dupla seleção: em primeiro lugar, a seleção dos bens protegidos penalmente, e dos comportamentos ofensivos destes bens, descritos nos tipos penais; em segundo lugar, a seleção dos indivíduos estigmatizados entre todos os indivíduos que realizam infrações a normas penalmente sancionadas (BARATTA, 2002, p. 161).

Destaca-se que a superação teórica do paradigma etiológico pelo crítico, como modelo de análise social, não se processou nos âmbitos do cotidiano. Tanto isso é verdade que o paradigma etiológico continua hegemônico na prática dos operadores do sistema jurídico.

Considerando-se essas premissas em relação aos processos de criminalização, parte-se em direção à análise da vinculação desses processos com a violência individual.

\section{A violência individual versus a violência es- trutural}

A discussão do conceito de violência de forma ampliada, levando em conta a violência estrutural ${ }^{3}$ e o conseqüente processo de criminalização das classes subalternas, escamoteia-se por meio da propagação simbólica do medo da violência individual. Esse processo é posto em movimento tanto pelas instituições formais do Estado (Poder Judiciário, Legislativo, instituições de ensino etc.), como pelas informais (família, mercado, igreja, meios de comunicação etc.). A manutenção do estado de medo faz-se necessária para legitimar a utilização do 
paradigma etiológico, sendo fundamental manter o sentimento do perigo (sentimento subjetivo de insegurança), gerando indignação e consensos silenciosos entre os setores sociais. A mídia, como instituição informal, contribui para edificar esse processo por meio de programas, matérias e artigos sensacionalistas, em que centraliza, sem base científica, dados alarmantes da violência urbana e do campo, transformando-a em espetáculo. O comportamento violento de indivíduos é transformado, assim, na violência a ser combatida, e o indivíduo - o criminoso praticante do delito - volta à centralidade como objeto do direito penal (ANDRADE, 2003).

A escola possui também, nesse contexto, um papel de formação ideológica, configurando-se como uma das instituições de socialização da cultura dominante. Ela surge na sociedade brasileira, importada dos países centrais, no início do século 19, com o objetivo de instruir e qualificar social e intelectualmente os sujeitos. Ao longo de sua existência, consolidou-se como um espaço de difícil acesso para os segmentos subalternizados socialmente.

O sistema de ensino, em sua versão contemporânea, continua exercendo a função declarada de socialização cultural, ainda que possua uma nova configuração com outras atribuições, como a formação profissional (SANTOS, 2004). E mesmo que a estrutura institucional tenha se flexibilizado e permitido, ao longo dos anos, o acesso de diferentes grupos sociais aos seus bancos, esta condição por si só não garante a permanência dos novos integrantes durante o processo de formação, pelo contrário, muitos vão ficando pelo caminho, barrados pelos mecanismos de seleção, baseados, dentre outros aspectos, no conceito do mérito (BARATTA, 2002). Para a parcela dos que permanecem na instituição, ainda existem outras formas de seleção, como as barreiras socioeconômicas presentes na sociedade capitalista.

A instituição escola também contribui para a manutenção da violência estrutural quando atua de forma violenta (violência institucional) contra os não aptos, rotulando-os como 'alunos difíceis', naturalizando uma prática de punição, mesmo que subjetivamente, para os 'não-capazes'. Pode-se, assim, observar que a escola, como instituição de socialização cultural, em toda sua extensão de tempo na vida dos sujeitos, contribui para a conservação da realidade social utilizando mecanismos de

[...] seleção, discriminação e marginalização. [...] Esta realidade se manifesta com uma desigual distribuição dos recursos e dos benefícios, correspondentemente a uma estratificação em cujo fundo a sociedade capitalista desenvolve zonas consistentes de subdesenvolvimento e de marginalização (BARATTA, 2002, p. 171).
Nós também fazemos parte da produção da violência, que vez por outra, está presente em nossas ações, mesmo que dificilmente nos reconheçamos como seres produtores dela. Antes, procuramos combatê-la como um inimigo externo, uma entidade abstrata, alheia, que se materializa na figura do outro,

[...] em geral, a fúria da violência tem algo a ver com a destruição do 'outro', 'diferente', 'estranho', com o que se busca a purificação da sociedade, o exorcismo de dilemas difíceis, a sublimação do absurdo embutido nas formas de sociabilidade e nos jogos das forças sociais (IANINI, 2004 apud SILVA, 2007, p. 133, grifos do autor).

Portanto, entende-se a violência não apenas como uma manifestação individual, mas inserida em "[...] uma fenomenologia global da violência, esta é aqui compreendida como repressão de necessidades reais e, portanto, violação ou suspensão de direitos humanos" (ANDRADE, 2003, p. 126), em que necessidades reais podem ser traduzidas por necessidades humanas ${ }^{4}$.

Nessas proposições, destacam-se sujeito e responsabilidade como conceitos=chave na compreensão do processo de construção (legal, dogmático e ideológico) do conceito universal da criminalidade, em que o indivíduo é concebido

[...] numa visão atomizada, isto é, com variáveis independentes e não dependentes das situações, e a responsabilidade penal, por via de conseqüência, como responsabilidade individual, baseada no livre-arbítrio, o sistema penal constrói um conceito de criminalidade ou violência criminal essencialmente vinculado à violência individual (esta concebida com potencialidade para delinqüir) (ANDRADE, 2003, p. 128).

\section{E ainda, suplementando:}

[...] a violência de grupo e a institucional são consideradas apenas em relação a ações de pessoas individuais, e não no contexto do conflito social que elas expressam. A violência estrutural e, em sua maior parte, a violência internacional, é excluída do horizonte do conceito de crime, ficando assim imunizada a relação entre criminalidade e estas formas de violência (ANDRADE, 2003, p. 128).

O resultado é o controle dos sujeitos e dos comportamentos, quais sejam os criminosos e seus crimes, através da aplicação da pena e da política criminal. Isso nos leva a considerar que "[...] a violência criminal adquire, na atenção do público, a relevância que deveria corresponder à violência estrutural e, em parte, contribui para ocultá-la e mantê-la" (ANDRADE, 2003, p. 145). 
Todo este processo esconde as causas da produção da violência, jogando sobre as classes subalternizadas a responsabilidade sobre sua produção. Nessa perspectiva, o grande inimigo a ser combatido em busca da paz é, sem dúvida, o criminoso; não qualquer um, mas o estigmatizado, o pobre e negro, aquele de quem já se espera que seja o criminoso (BARATTA, 2002).

Percebe-se que relacionar a violência com a criminalidade é lugar comum dos grandes veículos de comunicação. A repercussão e o poder que têm, somados a sua linha ideológica contribuem para consolidar o vínculo entre violência e criminalidade, quando estes propagam que o aumento de um se dá pelo aumento do outro. Tal visão processa a violência de forma limitada, e esconde o fato de suas expressões estarem intrinsecamente ligadas à ordem social estabelecida. Em outras palavras, pode-se afirmar que os interesses de classe presentes na sociedade capitalista concorrem, aliados às outras relações sociais, para a diferenciação do "[...] que é e o que não é violência, salientando, ao mesmo tempo, formas de violência consideradas benéficas ou prejudiciais para determinada ordem socialmente estabelecida" (SILVA, 2007, p. 132).

Eis, em síntese, a fórmula dos culpados utilizada nessa equação social: a soma do comportamento individual mais a impunidade resultando no aumento da violência (criminalidade), tal decodificação latente está presente no

[...] discurso oficial sobre violência que, colonizando todos os demais possíveis, e usando para interpretação das diversas formas de 'violência de rua', é dominante no senso comum (político, jurídico, jornalístico etc.) da sociedade brasileira, obstaculizando a apreensão mais profunda do fenômeno (ANDRADE, 2003, p. 144).

São esses os elementos utilizados nos discursos que insistem em apoiar o recrudescimento do controle social por meio da aplicação da legalidade do direito penal.

Uma atitude ou relação - ou mesmo um conceito - quando é construída como criminal, passa a ser enquadrada dentro da lógica violência e responsabilidade individual versus segurança pública, levando para escrutínio a descontextualização e a despolitização sociais. Da mesma forma que ao se identificar a "[...] potencialidade da violência (o mal) na conduta individual do 'criminoso' abstrai-se a violência definida como criminal de seu contexto e conteúdo global, das instituições e relações de poder, das conjunturas etc." (ANDRADE, 2003, p. 146). Pode-se afirmar, pelo exposto, que os processos que atribuem a um sujeito a etiqueta de criminoso são parte de um sistema de exploração social, em que, primeiro, há uma eleição das ações a serem crimi- nalizadas e, depois, a seleção, dentre todos os infratores, daqueles a receberem o rótulo de criminoso. Chama-se a atenção para isso, alertando que tal processo não é linear, e está perpassado por algumas condicionalidades ligadas, sobretudo, aos meios de acesso - geralmente, medido pelo poder econômico - que o sujeito selecionado possui em relação ao poder judiciário. O que também nos leva a dizer que tais condicionalidades serão ainda mais relativas se somarmos características físicas como a cor da pele - e sociais - como profissão, escolaridade, entre outras.

Munidos dessas reflexões, voltemos para o Serviço Social e a relevância desse debate para a categoria.

\section{Um debate para o Serviço Social}

Diante de uma realidade desafiadora, com muitos valores postos à prova em decorrência da individualização progressiva, da dificuldade de acesso à satisfação das necessidades básicas, de uma nova compressão do espaço-tempo, do aumento do desemprego, do medo etc, aumentam preocupações e instabilidades quanto à segurança física, justificando o recrudescimento do controle social da violência. Para a sociedade, de uma maneira geral, a percepção da violência se dá de forma equivocada, pois, credita ao criminoso a responsabilidade, origem e propagação dos atos violentos, associando-os, diretamente com a pobreza. Dessa forma, escondem-se as causas, que deram origem ao ato criminoso, presentes na estrutura desigual da sociedade capitalista.

Ao aproximarmos o Serviço Social desse debate, percebe-se o grau de importância de sua participação nessas discussões, visto que o assistente social se configura como um profissional que é cotidianamente chamado a intervir nas relações de violência, sejam elas explícitas ou implícitas.

O fazer profissional dos assistentes sociais é, de acordo com Nicolau (2004, p. 86), composto de processos de trabalho "[...] historicamente construídos e socialmente determinados pelo jogo de forças, que articulam uma dada totalidade social". Num âmbito maior, esse fazer insere-se na reprodução material e espiritual da força de trabalho, incidindo "[...] sobre a consciência dos outros indivíduos sociais e de si próprio, objetivando a mudança de atos e comportamentos". Tal profissional - em uma das suas muitas funções - integra, ao lado de outros profissionais, as bases que movem a operacionalização do direito penal. Com seus instrumentos técnico-operativos (por exemplo, pareceres e estudos sociais), o assistente social intervém diretamente nos processos judiciais que efetivam - ou não - direitos.

Não é objetivo deste artigo delimitar as formas que a atuação do assistente social contribui para a 
consolidação, ou não, do etiquetamento do delinqüente no âmbito social, porém, sinalizamos que este processo também se realiza em sua atuação, por entendermos que a prática profissional não se dá de forma neutra, mas imbricada nas contradições sociais, econômicas e culturais.

Dentro desse âmbito, vale destacar a formação do assistente social, por representar um momento privilegiado de apreensão de conceitos e técnicas que poderão subsidiar sua prática futura, ou seja, "tendo como base pressupostos que definem determinada visão de homem e de sociedade, pretende preparar pessoas para atuarem no concreto" (NICOLAU, 2004, p. 96). Vale pontuar que, ainda nesse contexto de formação, coloca-se a possível dicotomia entre a prática profissional e a teoria, e sobre essa questão a mesma autora ${ }^{5}$ argumenta:

[...] impõe-se questionar se a formação profissional deve se constituir em espaço privilegiado da teoria (abstração desvinculada da prática) ou se esse espaço necessariamente precisa ter, na prática, sua validação. Ao mesmo tempo, impõe-se questionar se o fazer profissional pode se caracterizar pela ação desvinculada da reflexão, mesmo que, implicitamente, toda ação humana suponha níveis de reflexão mais ou menos elaborados.

Longe de pôr termo a essa complexa discussão, aponta-se, em consonância com Nicolau ${ }^{6}$ que " [.... o isolamento do processo formativo, daquela formação que se efetiva no fazer profissional, por meio do trabalho, reduz o primeiro a uma abstração e o segundo ao ativismo." Não se pode descolar a reflexão sobre essa dicotomia da história da profissão que, ao longo de sua curta existência, esteve majoritariamente atrelada à intervenção em detrimento da produção de conhecimento, quadro que não há muito se vem tentando rever. O que se declara, nesse sentido, é que a formação do assistente social pode, tanto quanto possível, ser plural e comprometida com a transformação social, capacitando-o a atuar de forma crítica, atento às possibilidades, aos instrumentais e desafios. Entende-se, também, que tal patamar de especialização não se dá de forma automática, e sim com apurado rigor teórico-metodológico, oxigenado pelo permanente diálogo entre universidade e sociedade, num exercício para além dos muros visíveis e invisíveis.
No campo profissional, é pertinente que o assistente social desenvolva um sentido de alerta em relação ao perigo de adquirir uma visão determinista da realidade, o que o levaria a desenvolver uma prática apoiada na mera reprodução de rotinas burocratizantes.

O que ecoa dessas considerações é a indagação a respeito de como o assistente social, sendo um profissional comprometido com a transformação social, pode alterar tais relações? Entendemos como primeiros passos as produções teóricas que já aparecem nas questões relacionadas à violência ${ }^{7}$, no entanto, há muito para ser feito no que se refere à formação, com um destaque especial para:

a) uma formação de qualidade que possa subsidiar o profissional a romper com o senso comum no seu cotidiano, buscando uma base científica para aportar suas análises e intervenções. Base essa pautada numa construção crítica a respeito da realidade - como a apresentada pela criminologia crítica - aliada a outros saberes, como a antropologia, psicologia, sociologia etc.;

b) a necessidade de caminhar num processo de formação que incentive com firmeza o pluralismo e negue veementemente o ecletismo (SILVA, 2007);

c) a abertura de espaços no processo de formação para o diálogo além dos muros acadêmicos com os sujeitos que carregam as etiquetas de criminoso, marginal, e interacionar-se com eles. E, nesse exercício, construir pontes com o assistente social que intervém diretamente nas questões relacionadas à violência, tendo como finalidade submeter a prática e a formação à crítica permanente e radical, ultrapassando a denúncia da violência para passar a negá-la material e concretamente (SILVA, 2007).

Destarte, acreditamos que discutir as relações de violência é, também, discutir as relações sociais permeadas pelos interesses de classe. E nesse exercício, pensar no modo em que a categoria violência nos é apresentada. Não por menos a violência é vista comumente como resultado de um sistema de leis arcaicas que já não cumpre seu papel punitivo. Esse é o discurso que, ao invés de afirmar a superação do modelo penal, passa a legitimálo por meio do aumento da repressão social, ao mesmo tempo em que culpabiliza setores da população pelo aumento da criminalidade, já que se utiliza, ainda, do modelo etiológico da Escola Positiva do século 19 para identificar quem é, ou não, socialmente criminoso. 
Tal modelo criminológico continua possuindo status hegemônico no senso comum, sobretudo no dos operadores do sistema penal, apesar de ter sido teoricamente superado e não encontrar, como paradigma, nenhuma base teórica e empírica. Esse paradigma se mantém hegemônico porque confere ideologicamente sustentação a um modelo de combate à criminalidade. E é nesse sentido que se instaura uma problemática, pois sendo o assistente social um dos operadores do sistema penal, ele também é suscetível, assim como outros profissionais, a utilizar-se do discurso do senso comum em relação à produção da criminalidade, apoiado no paradigma etiológico quando de sua ação profissional. $\mathrm{O}$ que o levaria a uma apreensão restrita do real, aportada numa construção teórica que segmenta a sociedade por meio da seleção entre os bons e maus, protegendo os bons e punindo os maus. Apoiar-se em tais conceitos, para o assistente social, solidifica um discurso que é contrário ao promulgado pelo seu código de ética profissional, que defende a sua ação na direção de contribuir para a construção de uma ordem societária pautada na eqüidade e na justiça.

Romper com o paradigma etiológico é romper com a visão de que existe um criminoso nato, e passar a ver essa figura como uma construção social que encerra em si diversos fatores, e que é mantida e legitimada por interesses de classe, próprios da sociedade capitalista. É, também, abrir espaços para qualificar o debate sobre a violência, para além do indivíduo. É perceber que seguindo o modelo criminológico da Escola Positiva não se discute a violência, ou melhor, discute-se apenas parte das relações de violência.

Dentro desse contexto, a categoria violência camufla-se em duas questões: primeiro, no aumento da repressão social que incidirá sobre setores específicos da população, qual sejam os pertencentes às classes subalternas, muitas vezes por não possuírem meios para acessarem os mecanismos legais de defesa, ou, simplesmente, por já serem selecionados pelo sistema penal desigual; segundo, no processo que nega às classes subalternas o direito ao exercício da cidadania plena ${ }^{8}$ e as condições para a construção da autonomia, uma vez que não possuem acesso aos bens e serviços sociais, como saúde, educação etc.

Em relação a essas duas questões é que a discussão sobre a violência precisa ser realizada, e, para tanto, concordamos com Baratta (1997, p. 68), quando este diz que:

[...] é necessário sair do impasse, evitar, em primeiro lugar o círculo vicioso do eficientismo penal e, em segundo lugar, a criminalização da política social. [...] Não se trata simplesmente de desenhar o direito penal da Constituição, mas sim de redefinir a política segundo o desenho constitucional, como política de realização dos direitos.

É vital que todos nós, assistentes sociais ou não, como atores sociais que somos, passemos a considerar as relações de violência dentro de uma lógica global, e, nesse sentido, observemos que

[...] a necessidade de segurança da cidadania não é somente uma necessidade de proteção frente à criminalização e aos processos de criminalização: é uma necessidade de ser e sentir-se garantida em todos os direitos, o de existir, de ser livre, de desenvolver as próprias capacidades, de se expressar e se comunicar, de ter uma qualidade de vida digna e gratificante, de ter voz e poder influir sobre as condições das quais, concretamente, depende a forma própria de ser e existir (BARATTA, 1997, p. 69).

E, para atuar nesse contexto, o assistente social precisa ser um profissional

[...] qualificado, que reforce e amplie a sua competência crítica; não só executivo, mas que pensa, analisa, pesquisa e decifra a realidade. [...] O novo perfil é de um profissional afinado com a análise dos processos sociais, tanto em suas mediações macroscópias quanto em suas manifestações quotidianas; um profissional criativo e inventivo, capaz de entender o 'tempo presente, os homens presentes, a vida presente' e nela atuar, contribuindo, também para moldar os rumos de sua história (IAMAMOTO, 1998, p. 49, grifos da autora).

Reforçando o que foi dito, segue-se cantando com Mano Brown (2002) a esperança, quando este diz que é

[...] necessário sempre acreditar que o sonho é possível,

Que o céu é o limite e você, truta, é imbatível. 


\section{Referências}

ANDRADE, V. P. de. Sistema penal máximo versus cidadania mínima: códigos de violência na era da globalização. Porto Alegre: Livraria do Advogado, 2003.

. A ilusão de segurança jurídica: do controle da violência à violência do controle penal. Porto Alegre: Livraria do Advogado, 1997.

BARATTA, A. Criminologia crítica e crítica do Direito Penal: introdução à sociologia do Direito Penal. Tradução de Juarez Cirino dos Santos. Rio de Janeiro: Editora Revan, 2002.

. Defesa dos direitos humanos e política criminal. Discursos sediciosos: crime, direito e sociedade, Instituto Carioca de Criminologia. Rio de Janeiro: Revan, ano 2, n. 3, p. 57-69, 1997.

CARVALHO, R. de; IAMAMOTO, M. V. Relações sociais e Serviço Social no Brasil: esboço de uma interpretação histórico-metodológica. São Paulo: Cortez, 2004.

CHAUí, M. Discurso no Congresso Interamericano de Educação em Direitos Humanos em Brasília, ago. 2006. Disponível em: $<$ http://www.direitos.org.br index2.php? option $=$ com_content\&do_pdf=1\&id=1749-> . Acesso em: 30 mar. 2008.

FERRI, E. Princípios de Direito Criminal. Tradução de Luiz Lemos D’Oliveira. São Paulo: Saraiva, 1931.

GAROFALO, R. Criminologia: estudo sobre o delito e a repressão penal. Tradução de Júlio Matos. São Paulo: Teixeira e Irmãos Editores, 1983.

IAMAMOTO, M. V. O Serviço Social na contemporaneidade: trabalho profissional e formação profissional. São Paulo: Cortez, 2005.

LOMBROSO, C. O homem delinqüente. Tradução de Maristela B. Tomasini e Oscar A. C. Garcia. Porto Alegre: Ricardo Lenz Editor, 2001.

MANO BROWN. Racionais MC's. Nada como um dia após o outro dia. São Paulo: Zâmbia. 2002. CD, disco 1, faixa 10. (76 min).

MINAYO, M. C. de S. A violência na adolescência: um problema de saúde pública. Cadernos Saúde Pública, Rio de Janeiro, v. 6, n. 3, p. 278-292, 1990.

NICOLAU, M. C. C. Formação e fazer profissional do Assistente Social: trabalho e representações sociais. Serviço Social \& Sociedade. São Paulo, n. 79, p. 82-107, set. 2004.
OLIVEIRA, E. As vertentes da criminologia crítica. Cadernos da Pós-Graduação em Direito da Universidade Federal do Pará, Belém, v. 1, n. 3, p. 1-12, abr./jun. 1997. Disponível em: $<$ http://www.ufpa.br/posdireito/caderno3/ texto2_c3.html >. Acesso em: 14 dez. 2007.

PAULA, G. O ensino de criminologia na formação policial. 2007. Dissertação (Mestrado em Direito) - Universidade Federal de Santa Catarina, Centro de Ciências Jurídicas, Programa de Pós-Graduação em Direito, Florianópolis, 2007.

PEREIRA, P. A. P. Necessidades humanas: subsídios à crítica dos mínimos sociais. São Paulo: Cortez, 2002.

SANTOS, B. de S. A Universidade no século XXI: para uma reforma democrática e emancipatória da Universidade. São Paulo: Cortez, 2004.

SCHMICKLER, C. M. O protagonista do abuso sexual: sua lógica e estratégias. Chapecó/SC: Editora Argos, 2006.

SILVA, J. F. S. da. 'Justiceiros' e violência urbana. São Paulo: Cortez, 2004.

O recrudescimento da violência nos espaços urbanos: desafios para o Serviço Social. Serviço Social \& Sociedade, São Paulo, n. 89, p. 130-154, mar. 2007.

VELHO, G. (Org.). Desvio e divergência: uma crítica da patologia social. Rio de Janeiro: Zahar Editores, 1974.

\section{Notas}

$1 \mathrm{O}$ assunto abordado neste artigo está inserido nas pesquisas realizadas para o Programa de Educação Tutorial (PET) de Serviço Social, coordenado pela Professora María del Carmen Cortizo.

2 A criminologia interacionista, base teórica do labeling approach, considera que as questões centrais da criminologia, sua teoria e prática, não devem se voltar ao crime e ao delinqüente, mas, particularmente, ao sistema de controle adotado pelo Estado nos campos preventivo e normativo e na seleção dos meios de reação à criminalidade. Ao invés de se indagar os motivos pelos quais as pessoas se tornam criminosas, deve-se buscar explicações sobre os motivos pelos quais determinadas pessoas são rotuladas como delinqüentes, qual a fonte da legitimidade e as conseqüências da punição imposta a essas pessoas. São os critérios ou mecanismos de seleção das instâncias de controle que assumem a centralidade, e não a primazia dos motivos da delinqüência. Howard Becker, sociólogo norteamericano, é considerado o fundador do interacionismo criminológico(OLIVEIRA, 2007). 
3 Entende-se como violência estrutural “[...] aquela que nasce no próprio sistema social, criando as desigualdades e suas conseqüências, como a fome, o desemprego, e todos os problemas sociais com que convive a classe trabalhadora" (MINAYO, 1990, p. 290). Um exemplo desse modelo de violência é o apresentado por Chauí quando diz que "[...] as classes populares carregam o estigma da suspeita, da culpa e da incriminação permanente. A sociedade brasileira é uma sociedade em que a classe dominante exorciza o horror às contradições, promovendo a ideologia da união nacional a qualquer preço. Se recusa a trabalhar os conflitos, porque eles negam a idéia mítica da boa sociedade pacifica e ordeira." Ou ainda, numa sociedade em que "[...] as leis são armas para preservar privilégios, jamais tendo definido direitos possíveis para todos. Os direitos, na prática, são concessões e outorgas que dependem da vontade do governante. Em vez de figurarem um pólo público de poder e regulação dos conflitos, as leis aparecem como inúteis e inócuas, feitas para serem transgredidas e não transformadas. Uma situação violenta é transformada num traço positivo quando a transgressão é elogiada como um “jeitinho brasileiro"” (CHAUÍ, 2006, p. 2, grifo da autora).

4 Pereira (2002) discute tal conceito definindo as necessidades humanas básicas como 'saúde física' e 'autonomia'. Por tal discussão não ser foco deste trabalho, recomenda-se a obra.

5 Nicolau (2004, p. 96).

6 Id.

7 Como exemplo pode-se citar debates em torno da temática violência urbana (SILVA, 2004), violência contra criança e adolescente (SCHMICKLER, 2006), artigos nas revistas Serviço Social \& Sociedade e Revista Katálysis, para citar alguns.

8 Sobre essa questão ver Andrade (2003) no capítulo Do (pré) conceito liberal a um novo conceito de cidadania: pela mudança do senso comum sobre cidadania.

\section{Arnaldo Xavier}

Graduando de Serviço Social, Departamento de Serviço Social (UFSC)

Orientadora: Vera Regina Pereira de Andrade, Centro Ciências Jurídicas (CCJ/UFSC)

Bolsista do Programa de Educação Tutorial (PET) de Serviço Social
UFSC

Departamento de Serviço Social Campus Universitário Reitor João David Ferreira Lima

Trindade - Florianópolis - Santa Catarina CEP: 88010-970 